\title{
Sustained carbon uptake and storage following moderate disturbance in a Great Lakes forest
}

\author{
Christopher M. Gough,,${ }^{1,6}$ Brady S. Hardiman, ${ }^{2}$ Lucas E. Nave, ${ }^{3}$ Gil Bohrer, ${ }^{4}$ Kyle D. Maurer,${ }^{4}$ \\ Christoph S. Vogel, ${ }^{3}$ Knute J. Nadelhoffer, ${ }^{3,5}$ and Peter S. Curtis ${ }^{2}$ \\ ${ }^{1}$ Virginia Commonwealth University, Department of Biology, Box 842012, 1000 West Cary Street, \\ Richmond, Virginia 23284-2012 USA \\ ${ }^{2}$ Ohio State University, Department of Evolution, Ecology, and Organismal Biology, 318 West 12th Avenue, \\ Columbus, Ohio 43210-1293 USA \\ ${ }^{3}$ University of Michigan, Biological Station, 9133 Biological Road, Pellston, Michigan 49769 USA \\ ${ }^{4}$ Ohio State University, Department of Civil, Environmental and Geodetic Engineering, 2070 Neil Avenue, Columbus, Ohio 43210 USA \\ ${ }^{5}$ University of Michigan, Department of Ecology and Evolutionary Biology, 830 North University, \\ Ann Arbor, Michigan 48109-1048 USA
}

\begin{abstract}
Carbon (C) uptake rates in many forests are sustained, or decline only briefly, following disturbances that partially defoliate the canopy. The mechanisms supporting such functional resistance to moderate forest disturbance are largely unknown. We used a largescale experiment, in which $>6700$ Populus (aspen) and Betula (birch) trees were stem-girdled within a 39-ha area, to identify mechanisms sustaining $C$ uptake through partial canopy defoliation. The Forest Accelerated Succession Experiment in northern Michigan, USA, employs a suite of C-cycling measurements within paired treatment and control meteorological flux tower footprints. We found that enhancement of canopy light-use efficiency and maintenance of light absorption maintained net ecosystem production (NEP) and aboveground wood net primary production (NPP) when leaf-area index (LAI) of the treatment forest temporarily declined by nearly half its maximum value. In the year following peak defoliation, redistribution of nitrogen $(\mathrm{N})$ in the treatment forest from senescent early successional aspen and birch to non-girdled later successional species facilitated the recovery of total LAI to pre-disturbance levels. Sustained canopy physiological competency following disturbance coincided with a downward shift in maximum canopy height, indicating that compensatory photosynthetic $\mathrm{C}$ uptake by undisturbed, later successional subdominant and subcanopy vegetation supported C-uptake resistance to disturbance. These findings have implications for ecosystem management and modeling, demonstrating that forests may tolerate considerable leaf-area losses without diminishing rates of $\mathrm{C}$ uptake. We conclude that the resistance of $\mathrm{C}$ uptake to moderate disturbance depends not only on replacement of lost leaf area, but also on rapid compensatory photosynthetic $\mathrm{C}$ uptake during defoliation by emerging later successional species.
\end{abstract}

Key words: Betula; canopy defoliation; carbon cycling and sequestration; disturbance resistance; ecosystem management and resilience; leaf-area index, LAI; light-use efficiency; net ecosystem production; net primary production; northern Michigan, USA, forest; Populus; structure-function relationships.

\section{INTRODUCTION}

Disturbances that alter rates of forest $\mathrm{C}$ uptake are principal determinants of global terrestrial carbon (C) sink strength (Pan et al. 2011). Unlike severe standreplacing disturbances, moderate disturbances more subtly alter forest structure, and therefore are expected to have different consequences for ecosystem functions including $\mathrm{C}$ uptake and storage (Nave et al. 2011). Moderate disturbances that cause partial canopy defoliation, such as partial harvests, insect herbivory, disease, and age-related senescence, have mixed effects

Manuscript received 10 September 2012; revised 4 January 2013; accepted 10 January 2013. Corresponding Editor: C. C. Cleveland.

6.E-mail: cmgough@vcu.edu on trajectories of forest C uptake (Knohl et al. 2002, Birdsey et al. 2006, Lindroth et al. 2009, Luo and Weng 2011). In many forests, rates of $C$ uptake demonstrate unexpected resistance to partial canopy defoliation (e.g., Amiro et al. 2010). The mechanisms sustaining $C$ uptake following moderate disturbances are largely unresolved, however, with most studies emphasizing ecosystem structural and functional implications of severe standreplacing disturbance (Reich et al. 2001, Kaye et al. 2005). Identifying the mechanisms that sustain forest $C$ uptake following moderate disturbance will inform ecosystem managers and modelers concerned with maintaining and forecasting $\mathrm{C}$ sink strength.

Leaf-area index (LAI) replacement and the compensatory growth of undisturbed vegetation comprise important mechanisms facilitating $\mathrm{C}$ uptake resistance 
to disturbance (e.g., Law et al. 2001, Gough et al. 2007, Zha et al. 2009, Edburg et al. 2011). Amiro et al. (2010) tracked the annual net ecosystem production (NEP) of several different forests following moderate disturbance, reporting rapid recovery of $\mathrm{C}$ uptake to levels comparable to, or in some cases higher than, pre-disturbance rates as leaf area rebounded. Similarly, extensive canopy defoliation from insect herbivory or wind reduced NEP in temperate and subtropical forests, but with rapid recovery of LAI supporting full resilience of $\mathrm{C}$ uptake (Li et al. 2007, Amiro et al. 2010, Clark et al. 2010, Hicke et al. 2012). In contrast, studies conducted in managed forests offer examples of sustained $\mathrm{C}$ uptake and wood production following the silvicultural thinning of canopy dominant trees. For example, a twicethinned European beech (Fagus sylvatica) forest exhibited no decline in NEP or gross primary production (GPP) (Granier et al. 2008), and net primary production (NPP) was unaffected by the thinning of coniferous forests as subcanopy plant growth compensated for the removal of canopy dominant trees (Kaye et al. 2005, Campbell et al. 2009, Dore et al. 2010, Saunders et al. 2012).

Compensatory increases in growth and photosynthesis following moderate disturbance may be stimulated by the redistribution of limiting resources, sustaining $\mathrm{C}$ uptake during periods of low LAI. Natural disturbances and partial harvests that remove or kill only a fraction of canopy trees redirect light, nutrients, and water to undisturbed vegetation, rapidly improving the photosynthetic and growth performance of remaining vegetation in a variety of forest ecosystems (Mund et al. 2002, Kaye et al. 2005, Kirschbaum et al. 2007, Li et al. 2007, Martinez-Vilalta et al. 2007, Campbell et al. 2009, Dore et al. 2010, 2012, Saunders et al. 2012). Moderate disturbances that prompt spatially irregular mortality and canopy die-off may additionally enhance canopy structural heterogeneity and alter the distribution of leaf area, with implications for light distribution and the use of this resource to drive canopy photosynthesis (Covington and Aber 1980, Hardiman et al. 2011, 2013, Yang et al. 2011). Structurally heterogeneous forest canopies use light more efficiently to drive photosynthesis by distributing light evenly throughout the canopy and illuminating light-use efficient and often light-limited subcanopy leaves (Walcroft et al. 2005, Duursma and Makela 2007, Niinemets 2007, Pangle et al. 2009). Improved or sustained canopy light-use efficiency (LUE) following moderate disturbance thus may compensate for temporary leaf-area losses and maintain canopy physiological processes central to $\mathrm{C}$ uptake prior to the rebuilding of lost LAI.

In the present investigation we build on prior work conducted at the University of Michigan Biological Station (Pellston, Michigan, USA) that centers on a large-scale experimental manipulation designed to examine the mechanisms by which forest $\mathrm{C}$ uptake and storage respond to disturbance and ongoing succession, and to climate variation (Nave et al. 2011). In spring 2008, we initiated the "forest accelerated-succession experiment" (FASET) in which $>6700$ early successional canopy trees were stem-girdled within a 39-ha area, providing a systematic manipulation of forest canopy structure. Inventory and meteorologically based C-cycling measurements were conducted in separate control and treatment forests, permitting us to separate effects of disturbance from those of interannual climate variability. Nave et al. (2011), focusing on biogeochemical responses to moderate disturbance at our site, found that senescence of early successional species in the first two years following disturbance prompted nitrogen $(\mathrm{N})$ redistribution to the canopies of later-successional species, consequently buffering canopy LAI and NEP from declines. Here, we emphasize canopy processes, with the primary objective of identifying the canopy physiological mechanisms sustaining four-year C uptake (i.e., wood NPP and NEP) following moderate disturbance. We also discuss how canopy structural shifts may have facilitated C uptake resistance to moderate disturbance. Our findings offer new insights for forest managers and modelers, revealing how forest ecosystems may resist $\mathrm{C}$ uptake declines following moderate disturbance.

\section{Materials And Methods}

\section{Study site}

We conducted our study at the University of Michigan Biological Station (UMBS), in northern Michigan, USA $\left(45^{\circ} 35^{\prime} \mathrm{N}, 84^{\circ} 43^{\prime} \mathrm{W}\right)$. The study area is typical of maturing aspen-dominated forests in the upper Great Lakes region that developed following clearcutting and wildfires in the early 20th century (Gough et al. 2007). Bigtooth aspen (Populus grandidentata), now averaging $22 \mathrm{~m}$ tall and 90 years in age, dominates the forest canopy. This relatively short-lived early successional species is now in decline, along with trembling aspen (Populus tremuloides) and white birch (Betula papyrifera) (Gough et al. 2010). Longer-lived, later-successional canopy species including red oak (Quercus rubra), eastern white pine (Pinus strobus), sugar maple (Acer saccharum), red maple (A. rubrum), and American beech (Fagus grandifolia) are now increasing in relative dominance as early-successional species decline. Stem density of trees $\geq 8 \mathrm{~cm} \mathrm{dbh}$ is 700 800 individuals/ha, basal area is $\sim 25 \mathrm{~m}^{2} / \mathrm{ha}$, and leafarea index (LAI) averages 3.5. The mean annual temperature is $5.5^{\circ} \mathrm{C}$ and mean annual precipitation is $817 \mathrm{~mm}(1942-2003)$.

In 2008 we initiated an ecosystem-scale manipulation to identify how disturbance, succession, and ongoing climate change constrain long-term trajectories of $\mathrm{C}$ fluxes and storage in mixed temperate forests (see Nave et al. 2011). The "forest accelerated-succession experiment" (FASET), in which we stem-girdled $>6700$ earlysuccessional aspen and birch trees within a 39 -ha area in May 2008, is testing the overarching hypothesis that net ecosystem production (NEP) will increase as the canopy 


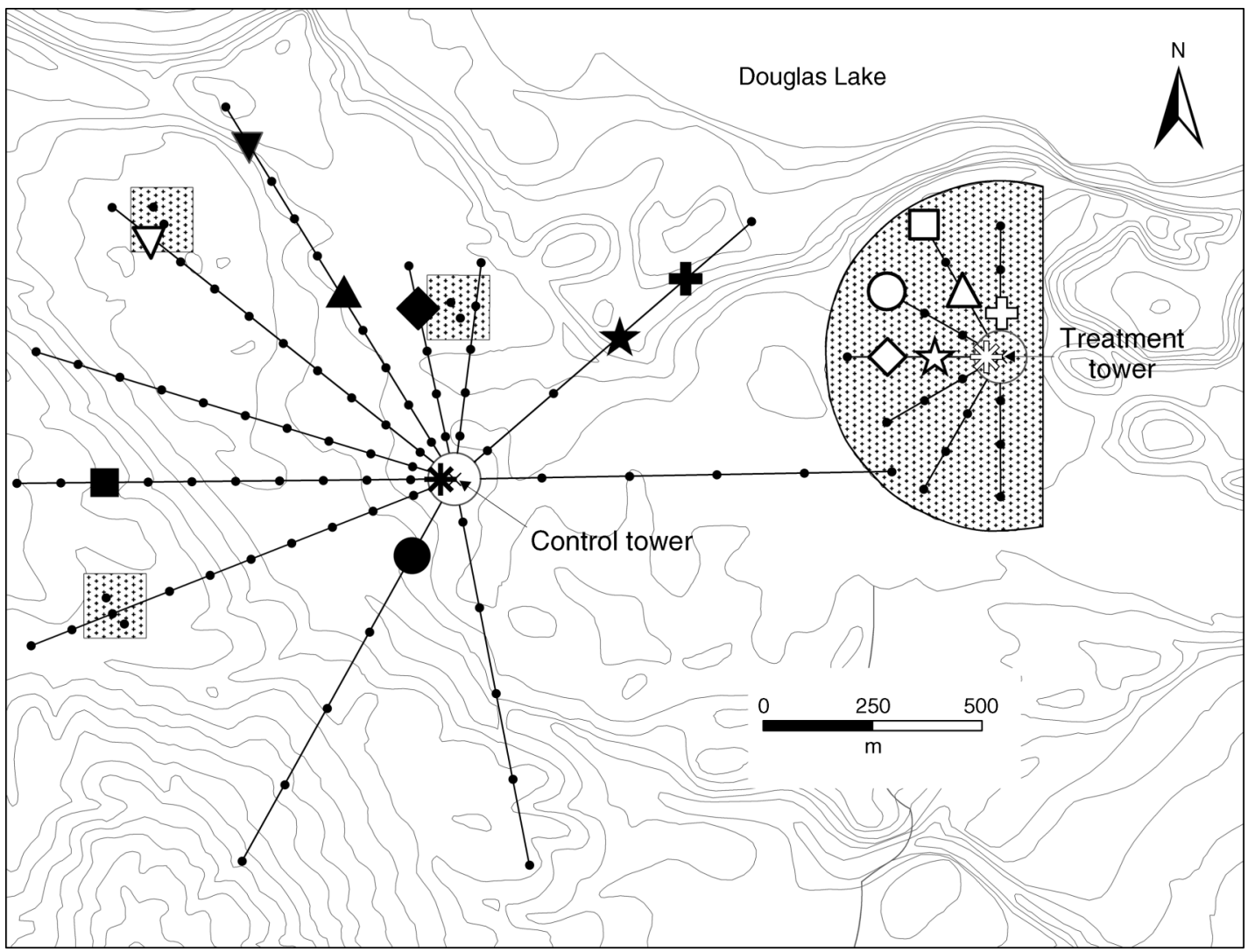

FIG. 1. The experimental layout of control and treatment forest plots and meteorological towers at the University of Michigan Biological Station (USA). Control and treatment forests house separate meteorological towers within 1.1-ha circular plots (large open circles) from which 0.1 -ha plots (small solid circles) radiate along linear transects. The 39-ha treatment forest (stippled fill) is composed of a 33-ha plot and three 2-ha plots in which all aspen and birch were girdled during spring 2008. On-the-ground measurements occur at various frequencies and spatial extents within control and treatment plots, with eight paired control (solid symbols) and treatment (open symbols) plots receiving priority because they encompass spatial variation in pretreatment aspen and birch dominance and site productivity.

becomes more biologically and structurally complex, and as nitrogen $(\mathrm{N})$ is redistributed from early- to latersuccessional canopy dominants. The girdling treatment is expediting mortality of aspen and birch, which comprised $39 \%$ of the pretreatment basal area, promoting development of a canopy that approximates projected regional changes in forest composition and structure (Nave et al. 2011). Surveys conducted in June 2011, three years following treatment, indicate $97 \%$ of girdled trees were dead or partially defoliated; however, we note that defoliation was heterogeneously distributed within the treatment forest, with aspen and birch comprising $14-48 \%$ of total LAI at the plot scale prior to girdling. This experimental disturbance, including the patchy distribution of mortality, is similar in severity and extent to moderate disturbances from wind, insects, and pathogens that result in partial canopy defoliation (Amiro et al. 2010). Experimental defoliation from girdling was compounded by patchy forest tent caterpillar (Malacosoma disstria) herbivory in 2010; this disturbance affected the control forest as well as the experimentally manipulated forest.
The experiment employs a suite of $\mathrm{C}$ and $\mathrm{N}$ cycling, and climate measurements within large paired treatment and unmanipulated control meteorological flux tower footprints (Fig. 1). Ground-based measurements are conducted in 81 and 22 permanent plots nested within the footprints of separate, unreplicated control and treatment meteorological towers, respectively, both of which measure the net ecosystem exchange (NEE) of $\mathrm{CO}_{2}$ between forest and atmosphere. The treatment tower is positioned to the east (predominantly downwind) of the main 33-ha treatment area and the control tower is in the un-manipulated forest $1.5 \mathrm{~km}$ to the west. Each tower is surrounded by a circular, 1.1-ha permanent plot of average landscape-level soil fertility, aboveground biomass, and canopy composition. Smaller plots $(0.1 \mathrm{ha})$ are located at $100-\mathrm{m}$ intervals along transects that radiate from each meteorological tower. Because this manuscript presents results from many collaborative projects occurring within the larger framework of the experimental manipulation, the number of plots sampled for each measurement parameter varies. We prioritized our ground-based measurements to 
include eight paired control and treatment plots with common pre-disturbance tree communities and productivity levels and that encompass landscape-level variation in biotic and abiotic properties.

\section{Leaf-area index}

We estimated LAI within treatment and control meteorological-tower footprints from measurements of overstory leaf-litter mass in 15 control and 14 treatment plots encompassing all of the paired control and treatment plots. Leaf litter was removed from three litter traps $\left(0.264 \mathrm{~m}^{2}\right)$ per plot weekly during leaf fall and monthly during other seasons, separated by species, dried, and weighed. LAI was calculated from species- and site-specific litterfall mass and specific leaf area (SLA) values (Gough et al. 2010).

\section{Canopy nitrogen mass}

We profiled the green-leaf chemistry of canopy species in four of the paired control and treatment plots to calculate growing-season canopy $\mathrm{N}$ stocks. For greenleaf chemistry, we used shotguns to collect three or more sun leaves from two to three individuals of each dominant canopy species within a plot during August of each year. Leaves were dried at $60^{\circ} \mathrm{C}$, ground in a ball mill, and assayed for percentage $\mathrm{N}$ on a Costech Analytical CHN analyzer (Costech International, Valencia, California, USA). We calculated species-level canopy $\mathrm{N}$ stocks as the product of annual litterfall mass, determined from litter traps, and species-specific foliar percentage $\mathrm{N}$ values.

\section{Aboveground wood net primary production}

We estimated aboveground wood mass $\left(M_{\mathrm{a}}\right)$ annually from 2007 through 2011 in each of 81 control and 22 treatment plots using allometric equations that relate bole diameter at $1.37 \mathrm{~m}$ height $(d)$ to $M_{\mathrm{a}}$ by

$$
M_{\mathrm{a}}=a \times d^{b}
$$

where $a$ and $b$ are species-specific coefficients developed from data collected at UMBS or obtained from published reports from the Great Lakes states and eastern North America (Gough et al. 2008). We measured $d$ annually on subsets of trees in control $(n=$ 700 of 8860 trees) and treatment ( $n=383$ of 2500 trees) forests with $d \geq 10 \mathrm{~cm}$ using band dendrometers. A sitespecific mean tissue-weighted fraction of $\mathrm{C}$ in bark, cork cambium, sapwood, and heartwood of the five dominant overstory species $(0.49)$ was used to convert dry wood mass to $\mathrm{C}$ mass. Annual aboveground wood NPP was the incremental change in total aboveground wood mass from one year to the next.

\section{Net ecosystem $\mathrm{CO}_{2}$ exchange, gross primary production, and ecosystem respiration}

We used eddy covariance to quantify fluxes of $\mathrm{CO}_{2}$ between the atmosphere and the forest canopy in control and treatment areas. Sensors were deployed at 34 and 46 $\mathrm{m}$ aboveground on the control tower and $32 \mathrm{~m}$ on the treatment tower. Wind velocity and temperature fluctuations were measured using three-dimensional sonic anemometers (model CSAT3 [Campbell Scientific, Logan, Utah, USA]); $\mathrm{CO}_{2}$ concentrations were sampled at $10 \mathrm{~Hz}$ using closed-path infrared gas analyzers (IRGAs; LI-COR models LI-6262 and LI-7000 [LICOR Biosciences, Lincoln, Nebraska, USA]) and compiled into half-hour block averages of net fluxes following the AmeriFlux protocol (Munger and Loescher 2006). Temperature measurements were converted to "real" temperature to account for crosswind velocity contamination (Kaimal and Gaynor 1991). $\mathrm{CO}_{2}$ concentrations were adjusted using the Webb, Pearman, and Leuning correction in a modified form derived by Detto and Katul (2007) as a correction for the $10-\mathrm{Hz}$ time series of the scalar. $\mathrm{CO}_{2}$ concentrations were further adjusted for IRGA attenuation using the spectral correction of Massman (2000).

Following Curtis et al. (2005), we defined three seasons within each calendar year: dormant, early, and late growing season. The 30-minute data within each season were further divided into daytime and nighttime observations, defined by above-canopy photosynthetically active radiation (PAR) measurements. Data were filtered based on a seasonal frictional velocity $\left(u^{*}\right)$ threshold criterion (Reichstein et al. 2005, Papale et al. 2006), with a prescribed maximum $u^{*}$ threshold of 0.35 $\mathrm{m} / \mathrm{s}$ (Curtis et al. 2005). Respiration was calculated using a site-specific empirical formula relating nighttime NEE to soil temperature (Schmid et al. 2003), with an added soil moisture coefficient in the growing season when respiration rates showed sensitivity to drought (Curtis et al. 2005). We used a bi-linear periodic method to fill gaps in temperature, moisture, humidity, and radiation observations, and assumed that $\mathrm{CO}_{2}$ fluxes during nighttime in all seasons and during the daytime in the dormant season were driven entirely by ecosystem respiration $\left(R_{\mathrm{e}}\right.$, the sum of autotrophic and heterotrophic respiration). We used the empirical respiration equations to gap-fill NEE during all nights and dormant-season days. Gaps in daytime GPP during the growing seasons were filled using the mean of 100 neural network simulations (Papale and Valentini 2003). Gap-filled gross primary production (GPP) was added to respiration to provide gap-filled NEE. Since the treatment tower sampled a footprint larger than the 33 ha of contiguous experimental girdling area, we used a footprint model modified from Detto et al. (2006) and the probabilistic flux footprint climatology (Chen et al. 2009) approach to scale our conclusions to fluxes originating only from the girdled area.

We assessed treatment effects on NEP, the annual sum of half-hourly NEE, by comparing fluxes measured at $34 \mathrm{~m}$ on the control and $32 \mathrm{~m}$ on the treatment tower. Despite the fact that measurements were done above the canopy, measurements that are conducted within the roughness sub-domain, which can extend as high as 4 
times the canopy height, can be biased by surface and forest features near the measurement location (Bohrer et al. 2009). Accordingly, our $\mathrm{CO}_{2}$ flux measurements at 32 and $34 \mathrm{~m}$ were consistently lower than at $46 \mathrm{~m}$, causing NEP reported in this manuscript to differ from previously published values from the control tower (e.g., Gough et al. 2008).

Principal drivers of interannual variability in NEP at our site include photosynthetic photon flux density (PPFD) and soil temperature $\left(T_{\mathrm{s}}\right)$. We measured PPFD above the canopy using PPFD sensors (LI-190SZ, LICOR Biosciences). We only present PPFD above the control-forest canopy because treatment PPFD sensors malfunctioned in 2009 and 2010; however, because control and treatment towers are $\sim 1 \mathrm{~km}$ apart, mean incoming above-canopy PPFD is similar between sites. Soil temperature was measured at $7.5 \mathrm{~cm}$ depth in one location during 2008 and 2009 and three locations thereafter near the base of each meteorological tower using type E thermocouples.

\section{Canopy structure}

We characterized canopy structural changes following disturbance in each of the eight paired control and treatment plots using a ground-based portable canopy LiDAR (PCL) system. The design, operation, and validation of this system is described in Parker et al. (2004) and was used previously at our site to relate canopy physical structure to wood NPP (Hardiman et al. 2011). The PCL is based on an upward looking, nearinfrared pulsed laser operating at up to $2000 \mathrm{~Hz}$ (model LD90-3100VHS-FLP, Riegl USA, Orlando, Florida, USA). Our system was mounted on a frame worn by the operator while walking along a transect that passed through the center of each plot. We ground-verified the operator's location by manually embedding a code in the LiDAR signal every $10 \mathrm{~m}$ along a pre-marked transect. We binned the raw data horizontally and vertically into $1-\mathrm{m}^{2}$ grids for structural analysis. From these data we derived two metrics of canopy structure: maximum canopy height and clumping index. Mean maximum canopy height was the average height across each transect of the uppermost bins with $>0$ LiDAR returns. We adapted the methods of Gonsamo et al. (2010) to estimate foliage-clumping indices of 0 to 1 for each plot. Values approaching 0 signify substantial foliar clumping and those close to 1 indicate uniform distribution of foliage.

\section{Percentage of absorbed photosynthetic photon flux density}

We inferred the percentage of PPFD absorbed by control and treatment canopies (fAPAR) over time from a site-specific relationship relating fAPAR to LAI. Below-canopy PPFD was recorded continuously at 1 $\mathrm{Hz}$ for 1-2 weeks during peak LAI in 2011 in each of nine control and three treatment plots using an array of eight sensors (LI-190 Quantum Sensor [LI-COR Biosciences] and SQ-110 Quantum Sensor [Apogee Instru- ments, Logan, Utah USA]) evenly spaced along $26 \mathrm{~m}$ spanning the diameter of each plot. Our sampling strategy encompassed a broad range of LAIs, from 2.2 to 6.3. Within each plot, we averaged PPFD across sensors and over time to minimize solar angle influence. A BF2 sunshine sensor (Delta-T Devices, Cambridge, UK) on the control meteorological tower measured above-canopy total and diffuse radiation. We used PPFD data to estimate AAPAR when the diffuse fraction of total radiation was $>85 \%$ to avoid inclusion of sunflecks (e.g., Tobin and Reich 2009). We calculated fAPAR by subtracting the quotient of mean below- and above-canopy PPFD from 1. We used nonlinear regression to relate fAPAR to LAI and then inferred peak growing season fAPAR (2007-2011) from mean control- and treatment-forest LAI measurements described above in Leaf-area index.

\section{Apparent quantum yield and maximum GPP}

We used a rectangular hyperbola function to describe the relationship between GPP and above-canopy PPFD and to derive canopy physiological parameters for control and treatment forests:

$$
\mathrm{GPP}=\frac{\alpha \mathrm{GPP}_{\max } \mathrm{PPFD}}{\mathrm{GPP}_{\max }+\alpha \mathrm{PPFD}}
$$

where $\alpha$ is apparent quantum yield and $G_{\text {max }}$ is potential maximum GPP. We included in our analysis only non-gap-filled half-hourly GPP values from June through August, excluding spring leaf emergence and autumn leaf fall. Apparent quantum yield $(\alpha)$ is a metric of LUE that indicates the responsiveness of GPP to increases in above-canopy PPFD (Clark et al. 2010).

\section{Statistical analyses}

For all response parameters except $\mathrm{C}$ fluxes derived from meteorological measurements, we compared treatment means and derived confidence intervals using timeseries ANOVA in which control and treatment plots nested within the meteorological tower footprints served as replicates. To simplify the presentation of our results, nonoverlapping 95\% confidence intervals shown in figures indicate significant differences among means at $\alpha=0.05$. Model parameters, $\alpha$ and $\mathrm{GPP}_{\max }$, derived from a rectangular hyperbolic function relating GPP to above-canopy PFFD were considered statistically different when their 95\% confidence intervals were nonoverlapping. We additionally examined trends over time in maximum canopy height using linear regression analysis. We conducted statistical analyses using SAS version 9.2 (SAS Institute 2009) and SigmaPlot 12 (SYSTAT 2011).

Confidence intervals for meteorological C fluxes were calculated using the daily-differencing approach developed by Hollinger and Richardson (2005). We used a conservative estimate of error by incorporating errors associated with our gap-filling techniques for ecosystem respiration $\left(R_{\mathrm{e}}\right)$ and GPP. Errors of $R_{\mathrm{e}}$ are pulled from 
the regression of our empirical $R_{\mathrm{e}}$ formulas. Errors for GPP were derived from the standard error of the 100 neural-network GPP simulations. A weighted average of these three half-hourly random errors is used to integrate yearly, seasonal, and process-specific random errors.

\section{RESULTS \\ Leaf-area index and canopy nitrogen following disturbance}

Stem-girdling of early successional canopy dominants in the treatment forest together with unanticipated insect herbivory prompted large interannual variation in leaf-area index (LAI) quantity and composition. Control-forest total LAI varied by $22 \%$ over five years (Fig. 2A). Contrastingly, total LAI in the treatment forest declined $44 \%$ from pretreatment levels three years following the girdling disturbance, coincident with patchy forest tent caterpillar (Malacosoma disstria) infestations in control and treatment forests. We did not separately quantify defoliation caused by stemgirdling and herbivory; however, a 50\% decline from 2009 to 2010 in non-girdled red oak LAI in the treatment forest suggests that this favored host species (Parry and Goyer 2004) experienced substantial herbivory. A smaller decline of $28 \%$ in red oak LAI occurred in the control forest. LAI recovered to pretreatment levels the following year as the leaf area of later successional species replaced that of severely diminished aspen and birch. Aspen and birch averaged $36 \%$ of total LAI in the control forest, with little variation from one year to the next. Aspen and birch in the treatment forest comprised $27 \%$ of total LAI prior to disturbance, declining to $1 \%$ four growing seasons following girdling as oak, pine, and maple dominance increased.

Interannual changes in LAI generally paralleled shifts in canopy $\mathrm{N}$ mass, with leaf $\mathrm{N}$ redistribution in the treatment forest from senescent early successional to non-girdled later successional species supporting total leaf-area recovery following defoliation (Fig. 2B). Control-forest canopy $\mathrm{N}$ mass averaged $44 \mathrm{~kg} / \mathrm{ha}$ over four years, including $26 \%$ allocated to aspen and birch. In the treatment forest, canopy $\mathrm{N}$ mass declined by $>10$ $\mathrm{kg} / \mathrm{ha}$ in 2010 when LAI reached a minimum. Treatment-forest recovery of total LAI to pre-disturbance levels in 2011, four years following disturbance, corresponded with the recovery and reinvestment of $\mathrm{N}$ in newly proliferated foliage of later successional species.

\section{Canopy structural shifts in response to disturbance}

Rapid deterioration of aspen and birch crowns in the treatment forest modified canopy structure by subtly shifting canopy height downward and increasing large spatial scale (i.e., inter-plot) canopy structural heterogeneity (Fig. 3). Canopy clumping indices (Gonsamo et al. 2010) were relatively stable over time in both forests; however, 95\% confidence intervals, which express variability among plots in clumping indices, increased
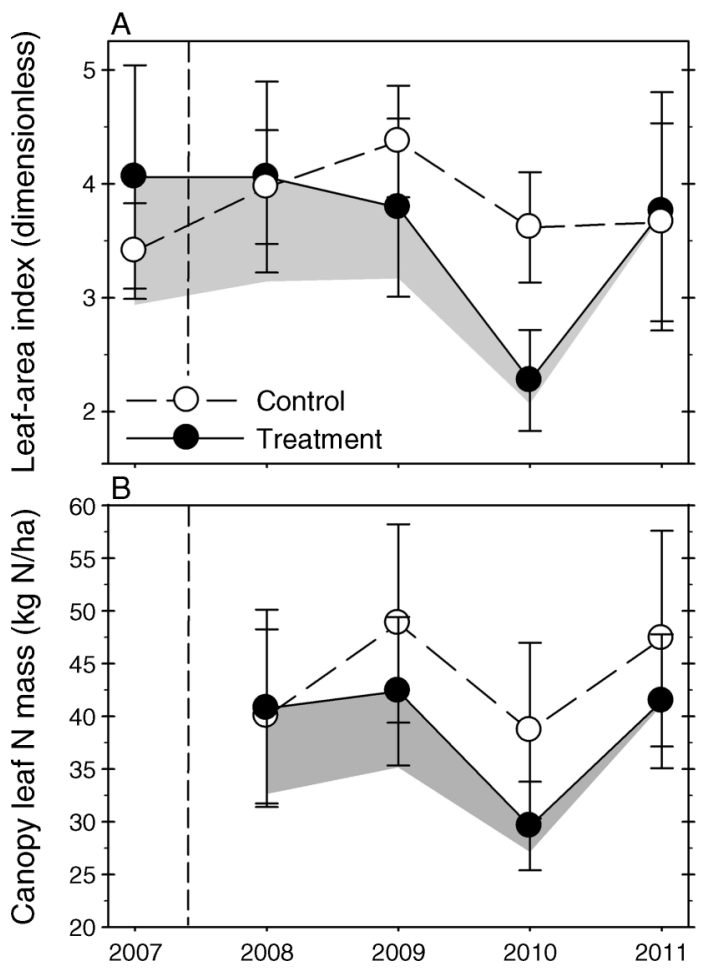

FIG. 2. (A) Leaf-area indices (LAI) of control and treatment forests, 2007-2011, and (B) the canopy leaf nitrogen (N) mass of control and treatment forests, 2008-2011. Values shown are means and 95\% CI. Gray-shaded areas illustrate aspen and birch contributions to treatment forest total LAI and canopy leaf $\mathrm{N}$ mass following moderate disturbance. The vertical dashed line indicates time of girdling in the treatment forest, and nonoverlapping $95 \%$ confidence intervals illustrate significant differences among means at $\alpha=0.05$.

threefold over three years in the treatment forest, indicating a broad spatial-scale increase in canopy structural heterogeneity. The rise in heterogeneity of clumping indices within the treatment forest may be related to spatially irregular mortality, with some areas of the canopy becoming more clumped as large clusters of aspen and birch aspen die, and others less clumped where mortality was diffuse. We also observed a marginally significant $(P=0.106)$ downward shift in maximum canopy height in the treatment forest, suggesting that aspen and birch decline exposed and increased in prominence lower-stature canopy leaf area.

\section{Canopy light absorption and physiology following disturbance}

The fraction of photosynthetically active radiation absorbed (fAPAR) by forest canopies varied minimally across a broad range of leaf-area indices, suggesting that partial defoliation of the treatment canopy had small effects on light absorption (Fig. 4, inset). Control and treatment forest plots with leaf-area indices of 2 to 6.5 spanned a relatively narrow fAPAR range of 0.85 to 0.98. Using the relationship between fAPAR and LAI, 

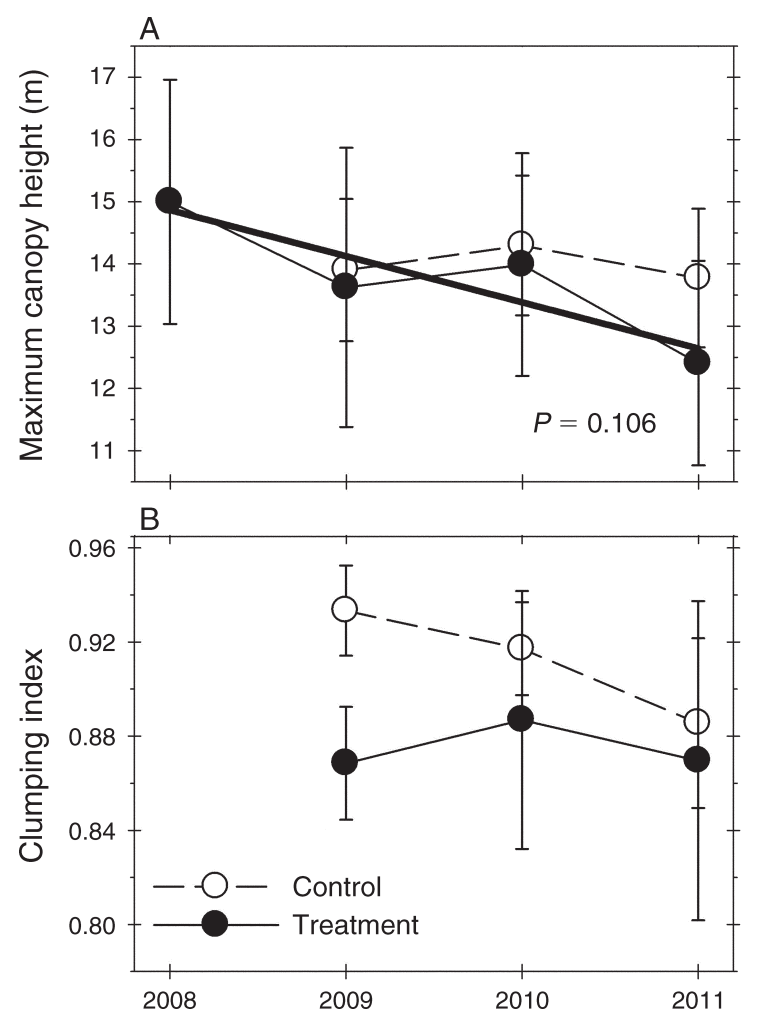

FIG. 3. (A) Control- and treatment-forest maximum canopy height and (B) clumping indices, 2008/9-2011, following girdling of aspen and birch in 2008. Values shown are means and $95 \% \mathrm{CI}$. Nonoverlapping $95 \%$ confidence intervals indicate significant differences among means at $\alpha=0.05$. we estimated that LAI declines of $44 \%$ in the treatment forest corresponded with a reduction in inferred fAPAR from 0.97 to 0.91 during peak defoliation in 2010 (Fig. 4). Inferred control forest fAPAR varied by $2 \%$ over the same five-year period, averaging 0.97.

Canopy physiological performance was sustained following disturbance to the treatment forest, even during peak defoliation. Canopy light-use efficiency (LUE), expressed as apparent quantum yield of the canopy, was significantly greater in the treatment forest during three of four years following experimental disturbance (Fig. 5A). Treatment differences in LUE were not observed during 2010, when defoliation peaked in the disturbed forest. Higher LUE in the treatment forest indicates greater sensitivity of mean hourly GPP to rising PPFD in the light-limited region of the lightresponse curve (Fig. 6). Conversely, potential canopy $\mathrm{GPP}_{\max }$ tended to be higher in the control forest, though this difference existed prior to the girdling treatment and was only significant one year (2011) following disturbance (Fig. 5B).

\section{Net primary and ecosystem production, ecosystem respiration, and gross primary production}

Net primary production (NPP) and net ecosystem production (NEP) did not differ significantly between treatments following moderate disturbance, as sustained canopy physiology and light absorption during peak defoliation and, subsequently, rapid LAI recovery maintained rates of $\mathrm{C}$ uptake and storage in aboveground wood mass. Aboveground wood NPP declined similarly in control and treatment forests to $\sim 1.1 \mathrm{Mg}$ $\mathrm{C} \cdot \mathrm{ha}^{-1} \cdot \mathrm{yr}^{-1}$ during 2010, recovering to a pre-disturbance level the following year (Fig. 7). Annual NEP in the control forest varied over 4 years from 1.71 to $3.38 \mathrm{Mg}$

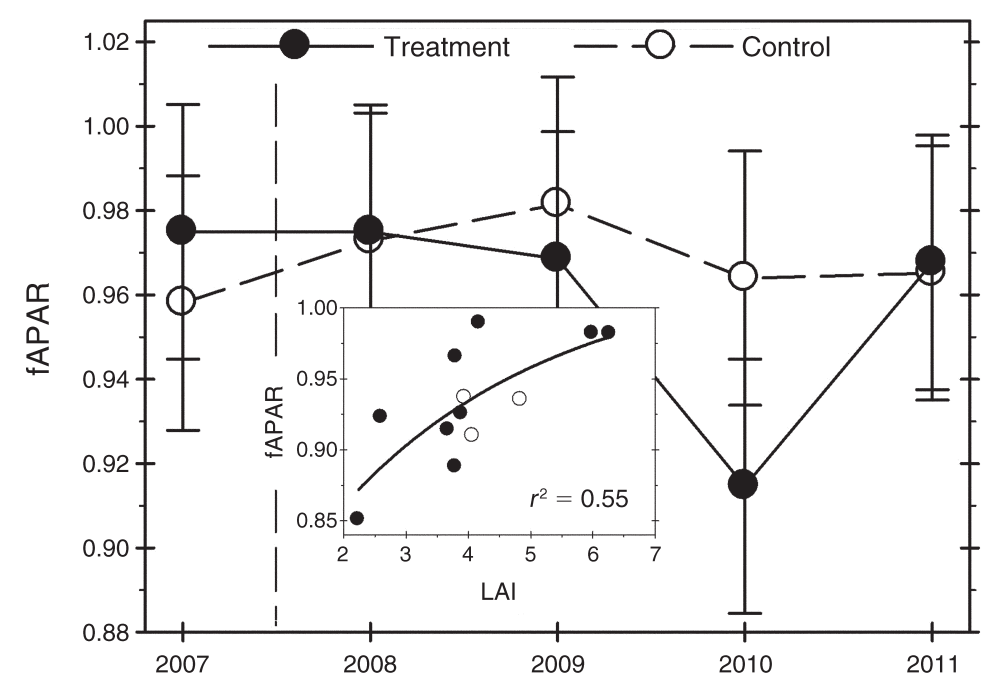

FIG. 4. The inferred fraction of absorbed photosynthetically active radiation (fAPAR) by control- and treatment-forest canopies, 2007-2011. Values shown are means and 95\% CI. The fAPAR was measured directly in 2011 and inferred for all other years from the inset relationship between fAPAR and leaf-area index (LAI); see inset. The vertical dashed line indicates time of girdling in the treatment forest. Nonoverlapping $95 \%$ confidence intervals indicate significant differences among means at $\alpha=0.05$. 

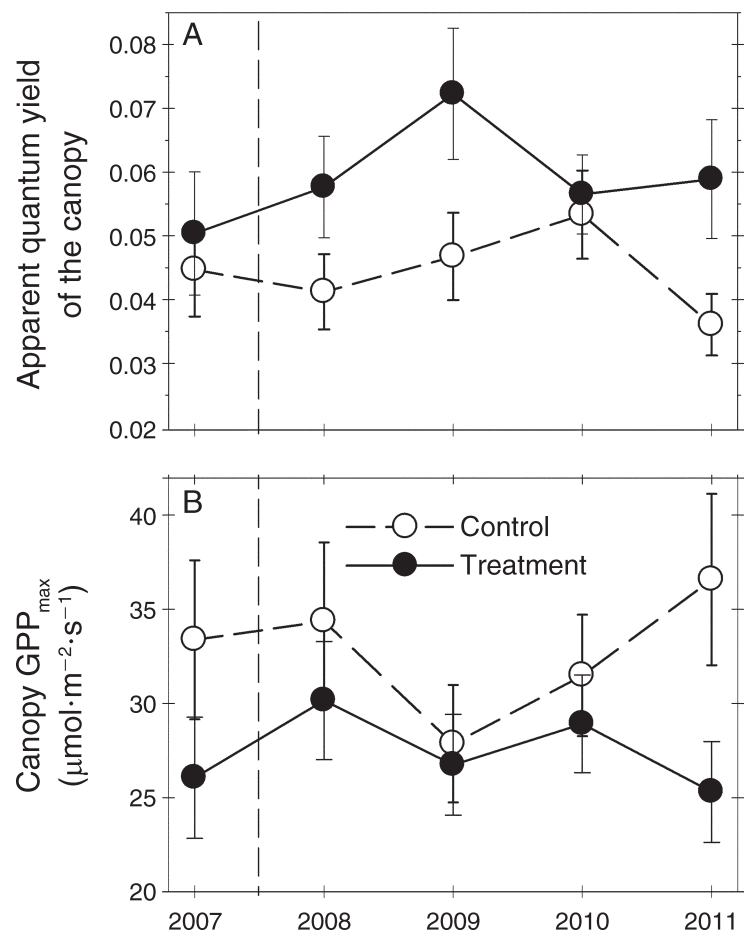

FIG. 5. (A) Apparent quantum yield of the canopy and (B) potential canopy maximum gross primary production $\left(\mathrm{GPP}_{\max }\right)$ for control and treatment forests, 2007-2011. Values shown are means and $95 \%$ CI. The vertical dashed line indicates time of girdling in the treatment forest, and nonoverlapping 95\% confidence intervals indicate significant differences among means at $\alpha=0.05$.

$\mathrm{C} \cdot \mathrm{ha}^{-1} \cdot \mathrm{yr}^{-1}$, with a slightly compressed range of 2.28 to 3.35 Mg C. $\mathrm{ha}^{-1} \cdot \mathrm{yr}^{-1}$ in the treatment forest (Fig. 8). As with NPP, comparable NEP minima occurred in both treatments during 2010, coincident with peak defoliation in the treatment forest; however, parallel declines in treatment and control forest $\mathrm{C}$ uptake rates together with relative LAI stability in the control forest suggest interannual climate variability, rather than disturbanceprompted defoliation, caused this period of low $\mathrm{C}$ uptake. Annual $R_{\mathrm{e}}$ (ecosystem respiration) was relatively high and GPP low in both treatments during 2010, with mean annual temperatures correspondingly high and growing season PPFD low.

\section{Discussion}

\section{Mechanisms sustaining $C$ uptake following moderate disturbance}

Our results suggest that forest $\mathrm{C}$ uptake resistance to decline following moderate disturbance was supported by the maintenance of canopy light-use efficiency (LUE) and light absorption during defoliation (years 1-3 posttreatment) and, subsequently, by the rapid replacement of lost leaf area (year 4). Our observation of net ecosystem production (NEP) resistance to moderate disturbance is consistent with that following the thinning of a deciduous forest (Granier et al. 2008), and comparable to studies showing only brief, temporary declines in leaf area and $\mathrm{C}$ uptake rates following insect herbivory, severe weather, or thinning (Amiro et al. 2010, Clark et al. 2010, Edburg et al. 2011, Goetz et al. 2012, Hicke et al. 2012). In our study, aboveground wood net primary production (NPP) and net ecosystem production (NEP) tracked one another in the control and treatment forests during the first three years following disturbance, indicating that interannual variation in $\mathrm{C}$ uptake was principally caused by year-to-year variability in climate parameters known to constrain gross primary production (GPP) and ecosystem respiration $\left(R_{\mathrm{e}}\right)$ at our site (Gough et al. 2008) rather than by disturbance. Low aboveground wood NPP and NEP in control and treatment forests three years following the girdling treatment, though coincident with peak defoliation in the moderately disturbed forest, corresponded with similarly low GPP and high $R_{\mathrm{e}}$ in both forests. We
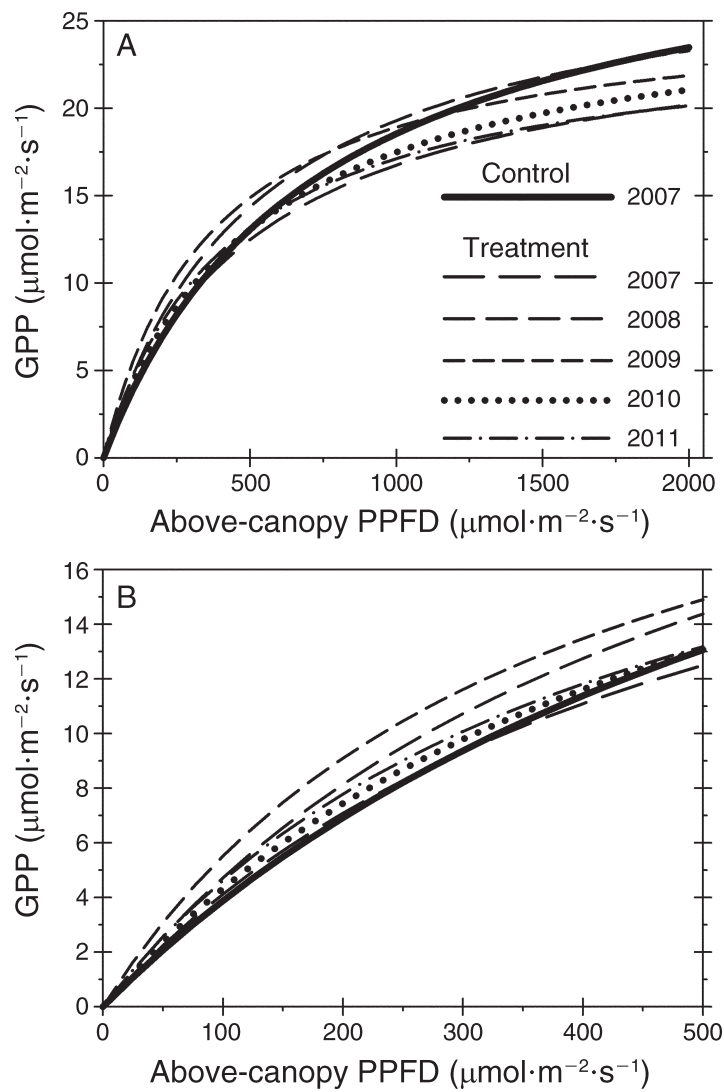

FIG. 6. Gross primary production (GPP) in relation to above-canopy photosynthetic photon flux density (PPFD) (A) from 0 to $2000 \mu \mathrm{mol} \cdot \mathrm{m}^{-2} \cdot \mathrm{s}^{-1}$ and (B) from 0 to 500 $\mu \mathrm{mol} \cdot \mathrm{m}^{-2} \cdot \mathrm{s}^{-1}$ for control (2007) and treatment (2007-2011) forests. Trend lines were derived and their parameter coefficients (shown in Fig. 5) compared statistically by fitting observations to a rectangular hyperbola function. For illustrative clarity, only the 2007 trend line is shown for the control forest; no significant differences were observed among trend lines of different years in the control forest. 


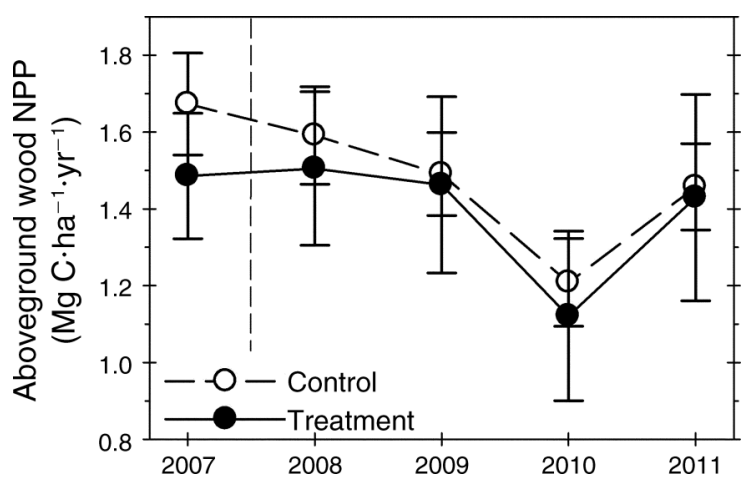

FIG. 7. Aboveground wood net primary production (NPP) of control and treatment forests, 2007-2011. Values shown are means and $95 \%$ CI. The vertical dashed line indicates time of girdling in the treatment forest, and nonoverlapping $95 \%$ confidence intervals indicate significant differences among means at $\alpha=0.05$.

cannot rule out that the forest tent caterpillar outbreak in 2010 contributed to low C uptake in both treatment and control forests because our analysis did not quantify the degree to which interannual variation in NEP was influenced by this unanticipated insect outbreak; however, leaf-area index (LAI) declines in the control forest were not significant, suggesting that insect defoliation played at most a secondary role in limiting $\mathrm{C}$ uptake and wood NPP during 2010. In the fourth year following disturbance, annual GPP of the treatment forest was slightly lower than that of the control forest, paralleling treatment differences in canopy $\mathrm{GPP}_{\max }$. Moderate disturbance temporarily reduced GPP in other forests (Misson et al. 2005, Li et al. 2007, Amiro et al. 2010, Clark et al. 2010, Dore et al. 2010, Edburg et al. 2011, Heliasz et al. 2011, Hicke et al. 2012). Notably, without the control forest for comparison, declining NEP in the first three years following treatment may have been erroneously attributed to disturbance, reinforcing the value of large-scale experiments with controls in partitioning the causes of interannual variability in $\mathrm{C}$ uptake.

A principal mechanism sustaining forest $\mathrm{C}$ uptake following moderate disturbance was the maintenance of canopy light absorption during peak defoliation. Inferred treatment-forest fAPAR (fraction of absorbed photosynthetically active radiation) suggests minor sensitivity to substantial leaf-area losses of $44 \%$ as aspen and birch declined in response to the girdling treatment. Multi-layered canopies with vertically stacked leaves generally maintain high rates of light absorption across a broad range of leaf-area indices (Niinemets et al. 1998, Niinemets 2007), suggesting that partial canopy defoliation minimally compromises fAPAR when LAI is sufficiently high prior to disturbance. Rising broad-scale canopy structural heterogeneity in the treatment forest may have provided an additional buffer against steep declines in fAPAR during peak defoliation. We observed a steady increase in the spatial variability of treatment-forest clumping indices, a shift that likely reflects differences in the extent and distribution of tree mortality within the large treatment-forest footprint. Structurally heterogeneous canopies absorb more light than structurally simple, uniform canopies (Chen 1996, Yang et al. 2006) and, consequently, may sustain high rates of $\mathrm{C}$ uptake through disturbance (Ahl et al. 2004, Ishii et al. 2004, Martin and Jokela 2004, O'Hara and Nagel 2006, Duursma and Makela 2007, Sprintsin et al. 2012). Our results thus elicit the hypothesis that forest canopies made structurally heterogeneous by moderate disturbance more effectively resist $\mathrm{C}$ uptake declines during peak defoliation by maintaining higher levels of light absorption than more structurally simple forests.

An additional primary mechanism supporting $\mathrm{C}$ uptake resistance to moderate disturbance was enhanced canopy LUE during defoliation. Apparent quantum yield of the canopy, a metric of LUE, was significantly greater in the treatment forest following moderate disturbance, though it declined and approached that of the control forest during the height of leaf-area loss in 2010. Moderate defoliation of other forest canopies improved or had no effect on LUE (Campbell et al. 2009, Clark et al. 2010). Our findings, and those of Clark et al. (2010), empirically demonstrate that moderate disturbance may increase canopy quantum yield while reducing $\mathrm{GPP}_{\max }$. Modeling studies additionally suggest that more structurally heterogeneous forest canopies, such as those that emerge following moderate disturbance, are more responsive to improved light availability under light-limited conditions (Walcroft et al. 2005, Duursma and Makela 2007, Hudiburg et al. 2009, Amiro et al. 2010). Though the exact reason for increased LUE following moderate disturbance is uncertain, partial defoliation of the upper canopy may illuminate more light-use-efficient foliage previously restricted to the canopy interior (Niinemets 2007).

Stability of canopy processes central to sustaining rates of $\mathrm{C}$ uptake following moderate disturbance, including fAPAR and LUE, suggests a critical shift in structure-function relationships occurred in which the photosynthetic contribution of undisturbed subdominant and subcanopy vegetation increased to compensate for defoliation of canopy dominant trees. Moderate upper-canopy defoliation increases light penetration into the canopy and more evenly distributes light between upper and lower canopy layers (Walcroft et al. 2005, Ueyama et al. 2006, Duursma and Makela 2007, Campbell et al. 2009, Hudiburg et al. 2009). As aspen and birch declined in the treatment forest, maintenance of fAPAR and LUE together with a general downward trend in canopy height indicate that enhanced light absorption by undisturbed subdominant and subcanopy vegetation boosted their photosynthetic contributions to GPP. Subdominant canopy plants are important contributors to $\mathrm{C}$ uptake and storage in forests, including those recently subjected to uppercanopy defoliation (Kaye et al. 2005, Ueyama et al. 

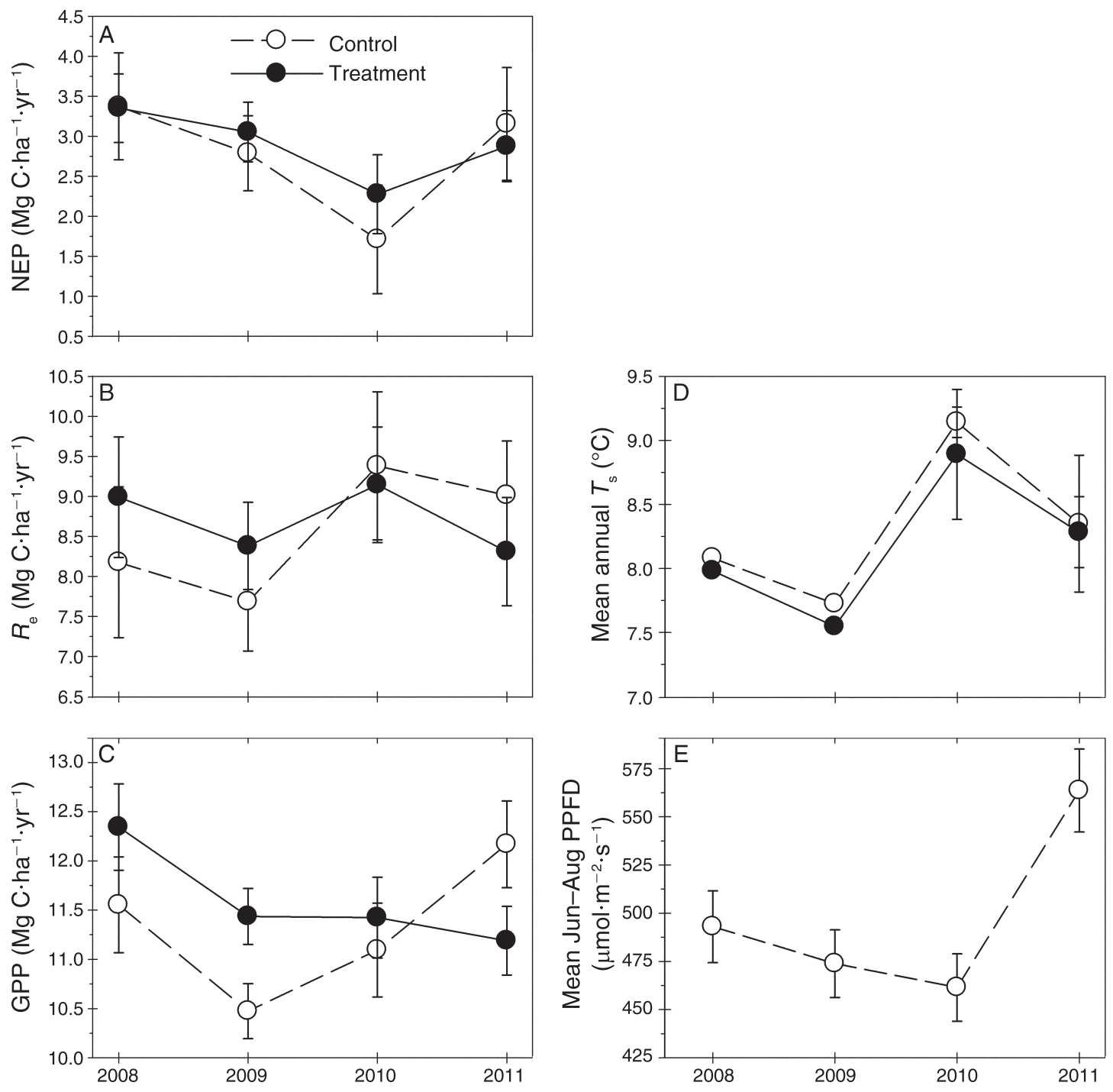

FIG. 8. (A) Net ecosystem production (NEP), (B) ecosystem respiration $\left(R_{\mathrm{e}}\right),(\mathrm{C})$ gross primary production (GPP), (D) mean annual soil temperature at $7.5 \mathrm{~cm}$ depth $\left(T_{\mathrm{s}}\right)$, and (E) mean June-August above-canopy photosynthetic photon flux density (PPFD) for control and treatment forests, 2008-2011. Values shown are means and 95\% CI. Only control-forest PPFD is shown because the treatment-forest sensor malfunctioned in 2009. Nonoverlapping $95 \%$ confidence intervals indicate significant differences among means at $\alpha=0.05$.

2006, Gough et al. 2007, Misson et al. 2007, Campbell et al. 2009, Dore et al. 2010).

In the year following the 2010 peak defoliation, leaf area and canopy $\mathrm{N}$ content in the treatment forest recovered to pre-disturbance levels as $\mathrm{N}$ reinvested in newly produced foliage of later successional canopy species offset $\mathrm{N}$ lost from senescent aspen and birch foliage. Rapid leaf-area recovery, as early as one year following disturbance, is an important mechanism supporting NEP resistance and resilience to moderate canopy defoliation in other forests (Li et al. 2007, Amiro et al. 2010, Clark et al. 2010, Hicke et al. 2012), with canopy $\mathrm{N}$ redistribution to undisturbed vegetation essential to rebuilding LAI lost to disturbance. At our site, Nave et al. (2011) reported initiation of foliar $\mathrm{N}$ redistribution in the treatment forest from girdled aspen to untreated maple canopy trees during the two years following disturbance, finding that cessation of $\mathrm{N}$ uptake by senescing aspen and birch enhanced available $\mathrm{N}$. We observed a complete redistribution of $\mathrm{N}$ from senescent to residual canopy trees four years following moderate disturbance in the same experimentally disturbed forest. The time required for newly available $\mathrm{N}$ to become fully reinvested in new leaf area depends on disturbance severity and the extent of $\mathrm{N}$ leaching (Clark et al. 2010), rates of plant senescence following disturbance (Zeller et al. 2008), and root-class-dependent rates of $\mathrm{N}$ mineralization, with larger roots decomposing and releasing inorganic $\mathrm{N}$ more slowly 
(Attiwill and Adams 1993, King et al. 1997, Smith et al. 2000, Silver and Miya 2001).

\section{Application}

Our findings support new forest-management paradigms that broadly emerging middle successional forests offer an array of important ecosystem services, while sustaining wood production at rates comparable to those of conventionally managed early successional forests (McGee et al. 1999, Lindenmayer et al. 2000). In our emerging middle-successional forest, aboveground wood NPP, a traditionally managed C flux, and net C uptake or NEP, an ecosystem service of increasing priority, were resistant to moderate disturbance as broad-scale canopy structural heterogeneity increased with the decline of early successional canopydominant species. These findings are particularly relevant because future terrestrial C-sink strength is highly uncertain as many North American forests, clear-cut harvested over a century ago, approach a successional transition in which early successional species are rapidly declining (Birdsey et al. 2006). Our results also contribute to a growing ecological foundation that suggests management practices cultivating greater, rather than less, forest structural heterogeneity could diversify and strengthen ecosystem services by enhancing structural features that may serve to sustain $\mathrm{C}$ uptake and encourage biological diversity (Crow et al. 2002, Schulte et al. 2007, Dyer et al. 2010). Likewise, management practices permitting, rather than actively preventing, moderate disturbances to emerging middlesuccessional forests may generate desired structural heterogeneity without compromising forest $\mathrm{C}$ uptake and storage (Dyer et al. 2010). This conclusion departs from previous recommendations that management broadly mitigate disturbances to preserve forest C-sink strength (Kurz et al. 2008), though clearly some forest ecosystems are vulnerable to even mild disturbance (Amiro et al. 2010) and the consequences of disturbancedriven changes in forest structure for $\mathrm{C}$ uptake requires further investigation.

Our experimental defoliation, while intended to mimic natural disturbance, suggests that wood production and C uptake may be sustained following moderate silvicultural thinning of maturing early-successional forests, particularly when already declining canopy-dominant species are harvested. Numerous studies demonstrate that partial harvests have short-term effects on wood production (e.g., Kaye et al. 2005, Chiang et al. 2008, Sabo et al. 2008, Campbell et al. 2009, Saunders et al. 2012) and C uptake (Misson et al. 2005, Dore et al. 2012, Saunders et al. 2012). As in our study, resistance of wood production and $\mathrm{C}$ uptake to precipitous declines following thinning is supported by the compensating photosynthesis and growth of unharvested vegetation (Mund et al. 2002, Martinez-Vilalta et al. 2007, Sabo et al. 2008). Prior results from our site additionally demonstrate that wood production is most resilient in stands comprised of a diverse assemblage of canopy species because improved growth of already intact, later-successional canopy species rapidly compensates for the loss of early-successional species (Gough et al. 2010). We caution that our targeted defoliation of early successional species through stem girdling deviates from silvicultural thinnings in two ecologically significant ways: carbon and nutrients were retained onsite and the extent and distribution of mortality was spatially irregular. Whether these subtly different structural consequences convey significantly different functional responses is uncertain (Amiro et al. 2010), indicating that additional investigation is required to determine how different types of moderate disturbance alter forest structure-function relationships.

Our findings have implications for ecosystem model simulations of $\mathrm{C}$ uptake and storage following moderate disturbance, demonstrating that LUE varies substantially over time and in response to disturbance, a result that suggests that model parameterizations using fixed LUE constants to scale forest production (e.g., see Ahl et al. 2004, Schwalm et al. 2006) may have limited predictive power in dynamic ecosystems. Our results additionally inform models and remote-sensing applications that use leaf area to simulate $\mathrm{C}$ uptake, revealing that some forests tolerate large LAI losses without corresponding declines in NEP, while some other studies report close coupling of $\mathrm{C}$ uptake rates and LAI (van Dijk et al. 2005, Luyssaert et al. 2007, Lindroth et al. 2008, Duursma et al. 2009). Our findings suggest that declines in NEP occur when a disturbance threshold is met that causes fAPAR and light use-efficiency to decline, with $\mathrm{C}$ uptake resistance to moderate disturbance varying substantially among forest types and with severity of disturbance (Amiro et al. 2010). Finally, our results and the findings of others suggest that representation of canopy structural heterogeneity in models may improve post-disturbance predictions of NEP (Cook et al. 2008, Sprintsin et al. 2012), though further investigation is required to establish this linkage. Identification of disturbance thresholds and the underlying mechanisms supporting functional resistance will improve the results of models simulating $\mathrm{C}$-cycling responses to moderate disturbance.

\section{Conclusions}

We continue to examine the mechanisms supporting C storage resistance to moderate disturbance. Presently, the response of NEP to moderate disturbance is less in magnitude than projected, with our initial hypothesis positing that NEP and LAI would decline in parallel following the stem-girdling of aspen and birch (see Nave et al. 2011). Instead, our experimental results are elucidating new, complementary mechanisms supporting unexpected $\mathrm{C}$ uptake resistance to moderate disturbance. Our principal findings indicate that substantial disturbance-prompted declines in leaf area can occur in some ecosystems with little corresponding change in 
rates of forest $\mathrm{C}$ uptake when fAPAR and LUE are maintained. Though $\mathrm{C}$ uptake in our forest was relatively insensitive to moderate disturbance, the threshold at which leaf-area losses cause canopy light absorption and light-use efficiency, and consequently $\mathrm{C}$ uptake, to decline clearly differs among ecosystems (Amiro et al. 2010, Hicke et al. 2012). Key questions remain regarding whether ecosystem models can adequately simulate observed C-cycling responses to moderate disturbance and, also, what disturbance thresholds prompt significant functional changes.

\section{ACKNOWLedgments}

We thank two anonymous reviewers for evaluating our first submission of the manuscript. This research was supported by the Climate and Environmental Sciences Division, Office of Science, U.S. Department of Energy (DOE) [DE-SC0006708] and by DOE's Office of Science [BER] through the Midwestern Regional Center of the National Institute for Climatic Change Research (NICCR) at Michigan Technological University [DE-FC02-06ER64158], with additional support from the National Oceanic and Atmospheric Administration [NA11OAR4310190]. G. Bohren and K. D. Maurer were funded in part by National Science Foundation (NSF) [DEB0911461]. K. D. Maurer and B. S. Hardiman were supported in part by an NSF IGERT fellowship (DGE-0504552) awarded through the University of Michigan BiosphereAtmosphere Research Training (BART) program. Some of the site measurements were conducted by participants of the UMBS Summer Research Experience for Undergraduates (REU) program through NSF [AGS- 0851421]. Any opinions, findings, and conclusions expressed in this material are those of the authors and do not necessarily reflect the views of the National Science Foundation.

\section{Literature Cited}

Ahl, D. E., S. T. Gower, D. S. Mackay, S. N. Burrows, J. M. Norman, and G. R. Diak. 2004. Heterogeneity of light use efficiency in a northern Wisconsin forest: implications for modeling net primary production with remote sensing. Remote Sensing of Environment 93:168-178.

Amiro, B. D., et al. 2010. Ecosystem carbon dioxide fluxes after disturbance in forests of North America. Journal of Geophysical Research: Biogeosciences 115(G4).

Attiwill, P. M., and M. A. Adams. 1993. Nutrient cycling in forests. New Phytologist 124:561-582.

Birdsey, R., K. Pregitzer, and A. Lucier. 2006. Forest carbon management in the United States: 1600-2100. Journal of Environmental Quality 35:1461-1469.

Bohrer, G., G. G. Katul, R. L. Walko, and R. Avissar. 2009. Exploring the effects of microscale structural heterogeneity of forest canopies using large-eddy simulations. BoundaryLayer Meteorology 132:351-382.

Campbell, J., G. Alberti, J. Martin, and B. E. Law. 2009. Carbon dynamics of a ponderosa pine plantation following a thinning treatment in the northern Sierra Nevada. Forest Ecology and Management 257:453-463.

Chen, B. Z., T. A. Black, N. C. Coops, T. Hilker, J. A. Trofymow, and K. Morgenstern. 2009. Assessing tower flux footprint climatology and scaling between remotely sensed and eddy covariance measurements. Boundary-Layer Meteorology 130:137-167.

Chen, J. M. 1996. Canopy architecture and remote sensing of the fraction of photosynthetically active radiation absorbed by boreal conifer forests. IEEE Transactions on Geoscience and Remote Sensing 34:1353-1368.

Chiang, J. M., R. W. McEwan, D. A. Yaussy, and K. J. Brown. 2008. The effects of prescribed fire and silvicultural thinning on the aboveground carbon stocks and net primary production of overstory trees in an oak-hickory ecosystem in southern Ohio. Forest Ecology and Management 255:1584-1594.

Clark, K. L., N. Skowronski, and J. Hom. 2010. Invasive insects impact forest carbon dynamics. Global Change Biology 16:88-101.

Cook, B. D., P. V. Bolstad, J. G. Martin, F. A. Heinisch, K. J. Davis, W. G. Wang, A. R. Desai, and R. M. Teclaw. 2008. Using light-use and production efficiency models to predict photosynthesis and net carbon exchange during forest canopy disturbance. Ecosystems 11:26-44.

Covington, W. W., and J. D. Aber. 1980. Leaf production during secondary succession in northern hardwoods. Ecology 61:200-204.

Crow, T. R., D. S. Buckley, E. A. Nauertz, and J. C. Zasada. 2002. Effects of management on the composition and structure of northern hardwood forests in Upper Michigan. Forest Science 48:129-145.

Curtis, P. S., C. S. Vogel, C. M. Gough, H. P. Schmid, H. B. Su, and B. D. Bovard. 2005. Respiratory carbon losses and the carbon-use efficiency of a northern hardwood forest, 1999 2003. New Phytologist 167:437-455.

Detto, M., and G. G. Katul. 2007. Simplified expressions for adjusting higher-order turbulent statistics obtained from open path gas analyzers. Boundary-Layer Meteorology 122:205-216

Detto, M., N. Montaldo, J. D. Albertson, M. Mancini, and G. Katul. 2006. Soil moisture and vegetation controls on evapotranspiration in a heterogeneous Mediterranean ecosystem on Sardinia, Italy. Water Resources Research 42.

Dore, S., T. E. Kolb, M. Montes-Helu, S. E. Eckert, B. W. Sullivan, B. A. Hungate, J. P. Kaye, S. C. Hart, G. W. Koch, and A. Finkral. 2010. Carbon and water fluxes from ponderosa pine forests disturbed by wildfire and thinning. Ecological Applications 20:663-683.

Dore, S., M. Montes-Helu, S. C. Hart, B. A. Hungate, G. W. Koch, J. B. Moon, A. J. Finkral, and T. E. Kolb. 2012. Recovery of ponderosa pine ecosystem carbon and water fluxes from thinning and stand-replacing fire. Global Change Biology 18:3171-3185.

Duursma, R. A., et al. 2009. Contributions of climate, leaf area index and leaf physiology to variation in gross primary production of six coniferous forests across Europe: a modelbased analysis. Tree Physiology 29:621-639.

Duursma, R. A., and A. Makela. 2007. Summary models for light interception and light-use efficiency of non-homogeneous canopies. Tree Physiology 27:859-870.

Dyer, J. H., S. T. Gower, J. A. Forrester, C. G. Lorimer, D. J. Mladenoff, and J. I. Burton. 2010. Effects of selective tree harvests on aboveground biomass and net primary productivity of a second-growth northern hardwood forest. Canadian Journal of Forest Research 40:2360-2369.

Edburg, S. L., J. A. Hicke, D. M. Lawrence, and P. E. Thornton. 2011. Simulating coupled carbon and nitrogen dynamics following mountain pine beetle outbreaks in the western United States. Journal of Geophysical Research: Biogeosciences 116.

Goetz, S. J., et al. 2012. Observations and assessment of forest carbon dynamics following disturbance in North America. Journal of Geophysical Research-Biogeosciences 117.

Gonsamo, A., J. M. N. Walter, and P. Pellikka. 2010. Sampling gap fraction and size for estimating leaf area and clumping indices from hemispherical photographs. Canadian Journal of Forest Research 40:1588-1603.

Gough, C. M., C. S. Vogel, B. Hardiman, and P. S. Curtis. 2010. Wood net primary production resilience in an unmanaged forest transitioning from early to middle succession. Forest Ecology and Management 260:36-41.

Gough, C. M., C. S. Vogel, K. H. Harrold, K. George, and P. S. Curtis. 2007. The legacy of harvest and fire on 
ecosystem carbon storage in a north temperate forest. Global Change Biology 13:1935-1949.

Gough, C. M., C. S. Vogel, H. P. Schmid, H. B. Su, and P. S. Curtis. 2008. Multi-year convergence of biometric and meteorological estimates of forest carbon storage. Agricultural and Forest Meteorology 148:158-170.

Granier, A., N. Breda, B. Longdoz, P. Gross, and J. Ngao. 2008. Ten years of fluxes and stand growth in a young beech forest at Hesse, north-eastern France. Annals of Forest Science 65:13.

Hardiman, B. S., G. Bohrer, C. M. Gough, C. S. Vogel, and P. S. Curtis. 2011. The role of canopy structural complexity in wood net primary production of a maturing northern deciduous forest. Ecology 92:1818-1827.

Hardiman, B. S., C. M. Gough, A. Halperin, K. Hofmeister, L. E. Nave, G. Bohrer, and P. S. Curtis. 2013. Maintaining high rates of carbon storage in old forests: a mechanism linking canopy structure to forest function. Forest Ecology and Management 298:111-119.

Heliasz, M., T. Johansson, A. Lindroth, M. Molder, M. Mastepanov, T. Friborg, T. V. Callaghan, and T. R. Christensen. 2011. Quantification of C uptake in subarctic birch forest after setback by an extreme insect outbreak. Geophysical Research Letters 38: L01704.

Hicke, J. A., et al. 2012. Effects of biotic disturbances on forest carbon cycling in the United States and Canada. Global Change Biology 18:7-34.

Hollinger, D. Y., and A. D. Richardson. 2005. Uncertainty in eddy covariance measurements and its application to physiological models. Tree Physiology 25:873-885.

Hudiburg, T., B. Law, D. P. Turner, J. Campbell, D. Donato, and M. Duane. 2009. Carbon dynamics of Oregon and northern California forests and potential land-based carbon storage. Ecological Applications 19:163-180.

Ishii, H. T., S. Tanabe, and T. Hiura. 2004. Exploring the relationships among canopy structure, stand productivity, and biodiversity of temperature forest ecosystems. Forest Science 50:342-355.

Kaimal, J. C., and J. E. Gaynor. 1991. Another look at sonic anemometry. Boundary-Layer Meteorology 56:401-410.

Kaye, J. P., S. C. Hart, P. Z. Fule, W. W. Covington, M. M. Moore, and M. W. Kaye. 2005. Initial carbon, nitrogen, and phosphorus fluxes following ponderosa pine restoration treatments. Ecological Applications 15:1581-1593.

King, J. S., H. L. Allen, P. Dougherty, and B. R. Strain. 1997. Decomposition of roots in loblolly pine: effects of nutrient and water availability and root size class on mass loss and nutrient dynamics. Plant and Soil 195:171-184.

Kirschbaum, M. U. F., H. Keith, R. Leuning, H. A. Cleugh, K. L. Jacobsen, E. van Gorsel, and R. J. Raison. 2007. Modelling net ecosystem carbon and water exchange of a temperate Eucalyptus delegatensis forest using multiple constraints. Agricultural and Forest Meteorology 145(1-2):48-68.

Knohl, A., O. Kolle, T. Y. Minayeva, I. M. Milyukova, N. N. Vygodskaya, T. Foken, and E. D. Schulze. 2002. Carbon dioxide exchange of a Russian boreal forest after disturbance by wind throw. Global Change Biology 8:231-246.

Kurz, W. A., G. Stinson, G. J. Rampley, C. C. Dymond, and E. T. Neilson. 2008. Risk of natural disturbances makes future contribution of Canada's forests to the global carbon cycle highly uncerain. Proceedings of the National Academy of Sciences USA 105:1551-1555.

Law, B. E., P. E. Thornton, J. Irvine, P. M. Anthoni, and S. Van Tuyl. 2001. Carbon storage and fluxes in ponderosa pine forests at different developmental stages. Global Change Biology 7:755-777.

Li, J. H., T. L. Powell, T. J. Seiler, D. P. Johnson, H. P. Anderson, R. Bracho, B. A. Hungate, C. R. Hinkle, and B. G. Drake. 2007. Impacts of Hurricane Frances on Florida scrub-oak ecosystem processes: defoliation, net $\mathrm{CO}_{2}$ ex- change and interactions with elevated $\mathrm{CO}_{2}$. Global Change Biology 13:1101-1113.

Lindenmayer, D. B., C. R. Margules, and D. B. Botkin. 2000. Indicators of biodiversity for ecologically sustainable forest management. Conservation Biology 14:941-950.

Lindroth, A., et al. 2008. Leaf area index is the principal scaling parameter for both gross photosynthesis and ecosystem respiration of Northern deciduous and coniferous forests. Tellus Series B: Chemical and Physical Meteorology 60:129142.

Lindroth, A., F. Lagergren, A. Grelle, L. Klemedtsson, O. Langvall, P. Weslien, and J. Tuulik. 2009. Storms can cause Europe-wide reduction in forest carbon sink. Global Change Biology 15:346-355.

Luo, Y. Q., and E. S. Weng. 2011. Dynamic disequilibrium of the terrestrial carbon cycle under global change. Trends in Ecology and Evolution 26:96-104.

Luyssaert, S., et al. 2007. $\mathrm{CO}_{2}$ balance of boreal, temperate, and tropical forests derived from a global database. Global Change Biology 13:2509-2537.

Martin, T. A., and E. J. Jokela. 2004. Developmental patterns and nutrition impact radiation use efficiency components in southern pine stands. Ecological Applications 14:1839-1854.

Martinez-Vilalta, J., D. Vanderklein, and M. Mencuccini. 2007. Tree height and age-related decline in growth in Scots pine (Pinus sylvestris L.). Oecologia 150:529-544.

Massman, W. J. 2000. A simple method for estimating frequency response corrections for eddy covariance systems. Agricultural and Forest Meteorology 104:185-198.

McGee, G. G., D. J. Leopold, and R. D. Nyland. 1999. Structural characteristics of old-growth, maturing, and partially cut northern hardwood forests. Ecological Applications 9:1316-1329.

Misson, L., et al. 2007. Partitioning forest carbon fluxes with overstory and understory eddy-covariance measurements: A synthesis based on FLUXNET data. Agricultural and Forest Meteorology 144:14-31.

Misson, L., J. W. Tang, M. Xu, M. McKay, and A. Goldstein. 2005. Influences of recovery from clear-cut, climate variability, and thinning on the carbon balance of a young ponderosa pine plantation. Agricultural and Forest Meteorology 130:207-222.

Mund, M., E. Kummetz, M. Hein, G. A. Bauer, and E. D. Schulze. 2002. Growth and carbon stocks of a spruce forest chronosequence in central Europe. Forest Ecology and Management 171:275-296.

Munger, J. W., and H. W. Loescher. 2006. Guidelines for making eddy covariance flux measurements. http://public. ornl.gov/ameriflux/sop.shtml

Nave, L. E., et al. 2011. Disturbance and the resilience of coupled carbon and nitrogen cycling in a north temperate forest. Journal of Geophysical Research: Biogeosciences 116.

Niinemets, U. 2007. Photosynthesis and resource distribution through plant canopies. Plant, Cell and Environment 30:1052-1071.

Niinemets, U., O. Kull, and J. D. Tenhunen. 1998. An analysis of light effects on foliar morphology, physiology, and light interception in temperate deciduous woody species of contrasting shade tolerance. Tree Physiology 18:681-696.

O'Hara, K. L., and L. M. Nagel. 2006. A functional comparison of productivity in even-aged and multiaged stands: a synthesis for Pinus ponderosa. Forest Science 52:290-303.

Pan, Y. D., et al. 2011. A large and persistent carbon sink in the world's forests. Science 333:988-993.

Pangle, L., J. M. Vose, and R. O. Teskey. 2009. Radiation use efficiency in adjacent hardwood and pine forests in the southern Appalachians. Forest Ecology and Management 257:1034-1042.

Papale, D., et al. 2006. Towards a standardized processing of Net Ecosystem Exchange measured with eddy covariance 
technique: algorithms and uncertainty estimation. Biogeosciences 3:571-583.

Papale, D., and A. Valentini. 2003. A new assessment of European forests carbon exchanges by eddy fluxes and artificial neural network spatialization. Global Change Biology 9:525-535.

Parker, G. G., D. J. Harding, and M. L. Berger. 2004. A portable LIDAR system for rapid determination of forest canopy structure. Journal of Applied Ecology 41:755-767.

Parry, D., and R. A. Goyer. 2004. Variation in the suitability of host tree species for geographically discrete populations of forest tent caterpillar. Environmental Entomology 33:14771487.

Reich, P. B., D. W. Peterson, D. A. Wedin, and K. Wrage. 2001. Fire and vegetation effects on productivity and nitrogen cycling across a forest-grassland continuum. Ecology 82:1703-1719.

Reichstein, M., et al. On the separation of net ecosystem exchange into assimilation and ecosystem respiration: review and improved algorithm. Global Change Biology 11:14241439.

Sabo, K. E., S. C. Hart, C. H. Sieg, and J. D. Bailey. 2008. Tradeoffs in overstory and understory aboveground net primary productivity in southwestern ponderosa pine stands. Forest Science 54:408-416.

SAS Institute. 2009. SAS version 9.2. SAS Institute, Cary, North Carolina, USA.

Saunders, M., B. Tobin, K. Black, M. Gioria, M. Nieuwenhuis, and B. A. Osborne. 2012. Thinning effects on the net ecosystem carbon exchange of a Sitka spruce forest are temperature-dependent. Agricultural and Forest Meteorology 157:1-10.

Schmid, H. P., H. B. Su, C. S. Vogel, and P. S. Curtis. 2003. Ecosystem-atmosphere exchange of carbon dioxide over a mixed hardwood forest in northern lower Michigan. Journal of Geophysical Research: Atmospheres 108.

Schulte, L. A., D. J. Mladenoff, T. R. Crow, L. C. Merrick, and D. T. Cleland. 2007. Homogenization of northern U.S. Great Lakes forests due to land use. Landscape Ecology 22:10891103.

Schwalm, C. R., et al. 2006. Photosynthetic light use efficiency of three biomes across an east-west continental-scale transect in Canada. Agricultural and Forest Meteorology 140:269286.
Silver, W. L., and R. K. Miya. 2001. Global patterns in root decomposition: comparisons of climate and litter quality effects. Oecologia 129:407-419.

Smith, C. K., M. R. Coyea, and A. D. Munson. 2000. Soil carbon, nitrogen, and phosphorus stocks and dynamics under disturbed black spruce forests. Ecological Applications 10:775-788.

Sprintsin, M., J. M. Chen, A. Desai, and C. M. Gough. 2012. Evaluation of leaf-to-canopy upscaling methodologies against carbon flux data in North America. Journal of Geophysical Research: Biogeosciences 117:G01023.

SYSTAT. 2011. SigmaPlot 12. SYSTAT, San Jose, California, USA.

Tobin, M. F., and P. B. Reich. 2009. Comparing indices of understory light availability between hemlock and hardwood forest patches. Canadian Journal of Forest Research 39:1949-1957.

Ueyama, M., Y. Harazono, E. Ohtaki, and A. Miyata. 2006. Controlling factors on the interannual $\mathrm{CO}_{2}$ budget at a subarctic black spruce forest in interior Alaska. Tellus Series B: Chemical and Physical Meteorology 58:491-501.

van Dijk, A., A. J. Dolman, and E. D. Schulze. 2005. Radiation, temperature, and leaf area explain ecosystem carbon fluxes in boreal and temperate European forests. Global Biogeochemical Cycles 19:15.

Walcroft, A. S., K. J. Brown, W. S. F. Schuster, D. T. Tissue, M. H. Turnbull, K. L. Griffin, and D. Whitehead. 2005. Radiative transfer and carbon assimilation in relation to canopy architecture, foliage area distribution and clumping in a mature temperate rainforest canopy in New Zealand. Agricultural and Forest Meteorology 135:326-339.

Yang, W. Z., D. Huang, B. Tan, J. C. Stroeve, N. V. Shabanov, Y. Knyazikhin, R. R. Nemani, and R. B. Myneni. 2006. Analysis of leaf area index and fraction of PAR absorbed by vegetation products from the terra MODIS sensor: 20002005. IEEE Transactions on Geoscience and Remote Sensing 44:1829-1842.

Yang, Y. H., Y. Q. Luo, and A. C. Finzi. 2011. Carbon and nitrogen dynamics during forest stand development: a global synthesis. New Phytologist 190:977-989.

Zeller, B., J. X. Liu, N. Buchmann, and A. Richter. 2008. Tree girdling increases soil $\mathrm{N}$ mineralisation in two spruce stands. Soil Biology and Biochemistry 40:1155-1166.

Zha, T., et al. 2009. Carbon sequestration in boreal jack pine stands following harvesting. Global Change Biology 15:1475-1487. 